\title{
Arbor
}

\section{Imprenta y lectura en Córdoba (1556-1900)}

María José Porro Herrera

Arbor CLXVI, 654 (Junio 2000), 253-275 pp.

Están a punto de cumplirse los cien años desde que viera la luz en 1900 La imprenta en Cordoba de José M. ${ }^{a}$ Valdenebro después de haber sido premiada por la Biblioteca Nacional en el concurso público de 1896. Algunas cosas nuevas, no demasiadas, se han escrito sobre el particular tras esta edición y todas ellas resultan ser deudoras en mayor o menor medida de la de Valdenebro, lo que indica la solidez de lo allí aportado por su autor. Bibliotecas árabes primero, imprenta después, el camino de la lectura y especialmente el de su difusión, no siempre ha guardado un ritmo uniforme entre los cordobeses.

Varios siglos habían transcurrido desde que la rica biblioteca califal de Alhakem II en los tiempos Omeyas ${ }^{1}$ se viera dispersada como consecuencia de las guerras civiles en los estertores del califato primero ${ }^{2}$ y tras la conquista de Córdoba por Fernando III más tarde junto con otras bibliotecas cordobesas si bien menos cuantiosas en sus fondos, no por ello menos interesantes, según se desprende de las escasas listas de venta de algunas de ellas de las que hemos podido tener noticias.

Frente a la riqueza de las bibliotecas arábigo-cordobesas y el aparente interés que sus dueños manifestaron por los libros y la cultura que de ellos irradiaba ${ }^{3}$, el aparente distanciamiento de sus herederos más tardíos y la evidente pobreza de la primitiva imprenta cuando se instala en Córdoba en el año de 1556. Carecemos todavía de un estudio que exceda lo bibliográfico y se adentre más bien por la investigación socio-histórica como se ha hecho para la Historia del libro en Francia y en menor medida en España para las ciudades de Valladolid, Lorca o Salamanca ${ }^{4}$..., que permita determinar quiénes poseían siquiera una pequeña biblioteca, además de las que sin lugar a dudas 
se albergaban en las casas de la nobleza, los libros que en mayor o menor cuantía reunieran los profesionales liberales así como algunos artesanos y las bibliotecas conventuales y monacales, cuyos fondos en Córdoba, salvo los de Carmelitas Calzados - hoy en el convento de San Cayetano-, fueron incautados mayoritariamente en las sucesivas desamortizaciones de 1823 y $1835^{5}$, y trasladados físicamente a nuevas dependencias desde la creación de la Biblioteca Provincial según Ley de 23 de octubre de 1820, en cuya operación se calcula que debieron perderse muchísimos más volúmenes de los hoy custodiados y conservados en la Biblioteca Pública Provincial de Córdoba, heredera y continuadora de la originaria ${ }^{6}$ y cuya reconstrucción aproximada se ha hecho en algún caso siguiendo las marcas de propiedad que conservan sus páginas ${ }^{7}$. Bibliotecas como la del Cabildo de Córdoba, nacida a partir de compraventas y donaciones; las del Obispado y la del antiguo Colegio de la Asunción - hoy custodiada en el I.E.S Séneca, conocida como «el tesoro»- fueron otros tantos lugares donde se refugiaron los saberes y los estudiosos cordobeses en buena sintonía.

Carecemos también de información documentada acerca de cuáles fueran las preferencias lectoras de los cordobeses, si bien no es arriesgado arguir que, como en el resto de España en cada momento, unos serían los intereses y por consiguiente los gustos de los más ilustrados -no olvidemos el círculo literario sevillano renacentista en torno a Juan de Mal Lara, Herrera, Pacheco, etc. y su irradiación más que probable en ámbitos cordobeses ${ }^{8}$ - y de quienes por su profesión —clérigos, médicos, juristas, etc. - hacían del libro instrumento de trabajo, y otros atraerían a los iletrados, cuyo contacto con la lectura no traspasaría los niveles de «lectura oída», como estudia Margit Frenk ${ }^{9}$ y como puede documentarse para épocas más tardías - fines del XVIII y XIX- mediante la relación de "papeles sueltos» $y$ «hojas volantes» sin fecha de edición las más de las veces, salidas de las prensas de D. Juan García Rodríguez años antes de aparecer la segunda (p. XII). Aun así, el número de impresos que vieron la luz en esta ciudad durante los siglos XVI y XVII no deja de ser importante: 278 en total.

La ubicación de Córdoba convirtió a la ciudad desde los más remotos tiempos en cruce de caminos y por ende de culturas ${ }^{15}$. No vivía sus mejores años cuando la imprenta comenzaba a consolidarse como industria floreciente, por lo que no es infrecuente ver cómo muchos de sus profesionales trasladan sus prensas a otra ciudad, atraídos por la esperanza del progreso o solicitados por algún encargo. No figura ningún nombre extranjero entre los tipógrafos del siglo XVI aquí residentes y tanto éstos como sus herederos del XVII desarrollarán em- 
presas de no excesiva duración ni relevancia, raramente especializados en algún tema, y sólo en contados casos, los de Gabriel Ramos Bejarano y Francisco de Cea Tesa, tendrán continuidad en sus herederos. Pero no hay que llamarse a engaño: la cercanía de ciudades como Sevilla y Granada con secular tradición universitaria, reconocido prestigio artístico y mayor disponibilidad económica, ejercían de imán irresistible para cuantos querían subir escaños en su aventura profesional: en más de una ocasión, Córdoba, al igual que otras ciudades andaluzas, debió servir de refugio pasajero a impresores que buscaban asentamiento definitivo y más productivo en cualquiera de las otras dos capitales vecinas, pero aun contando con esta circunstancia, podemos afirmar que Córdoba contó con profesionales dignos que, unas veces por encargo y otras por iniciativa propia, consiguieron no dejar relegada a la ciudad y a sus habitantes de uno de los cauces por los que sin lugar a dudas transcurre la savia de la cultura.

No faltan tampoco los llamados por Valdenebro «impresores de un solo parto» - Manuel de Cea y Francisco García, en el siglo XVIIa causa de no aparecer sus nombres más que en una ocasión y nunca en obra de relevancia. También figuraron talleres a nombre de dos viudas, la de Andrés Barrera, Lucía de Leerie, y la de Juan Martín, meras «razones sociales» en virtud de las cortapisas y limitaciones que los gremios impusieron a las mujeres a la hora de regentar un taller tipográfico, no sólo en España sino en el resto de Europa, y así, cuando la imprenta quedaba a cargo de la viuda, obligaban a la mujer o bien a contratar oficiales si el negocio requería la aplicación de la fuerza física, o bien a liquidarlo; eso explica el escaso tiempo que algunos talleres perrnanecían abiertos trasla muerte del titular, con la consiguiente emigración de útiles a otros talleres, o el frecuente nombre de la «razón social» a menudo tras el matrimonio de uno de los operarios con la viuda. Las obligaciones de las ordenanzas gremiales no fueron derogadas hasta 1790 , por lo que hemos de considerar casi excepcional la actividad realmente considerable de la viuda de Andrés Barrera.

Fueron las primeras imprentas de carácter ambulante como las de Juan Bautista Escudero, Gabriel Ramos Bejarano, entre otros, con un material escaso y no siempre de excelente calidad, circunstancia que en ocasiones se solventaría con el acopio de otros tipos más nuevos y letrería variada: góticos, redondos e incluso algunos alfabetos griegos ${ }^{16}$. Lo esporádico de su estancia en Córdoba no es óbice para que Ramos Bejarano diera a luz varios impresos de relevancia no ya tipográfica sino científica, como fueron Las obras del maestro Fernán Pérez de 
Oliva (1585) y Los cinco libros postreros de la Coronica General de Fspaña (1586) que continuara Ambrosio de Morales a partir de Florián de Ocampo. A ellas hay que añadir dos sermones de Álvaro Pizaño de Palacios (1606 y 1609), orador relevante en su época y unos Discursos para todos los Evangelios (1620), de Gaspar López Serrano, para lo cual hubo de desplazarse desde Sevilla, donde había establecido su residencia en 1609.

En el tránsito de los siglos XVI y XVII merece reseñar la figura de Francisco de Cea, que encabeza la dinastía de impresores cordobeses a los que vemos trabajando hasta los primeros años del XVIII. Sería continuado por sus hijos Salvador y Manuel de Cea Tesa y su nieto Francisco Antonio de Cea Paniagua, hijo de Salvador. Su producción se centra en sermones y tratados religiosos. Mayor importancia adquiriría el taller en manos de Salvador (1620-1661) «el mejor, y por largas temporadas el único, impresor de Córdoba» en palabras de Valdenebro (p. XX). Salvador diversifíca la temática a la que atiende: poesía -Rimas, de D. Miguel Colodrero de Villalobos-, consejos políticos, Medicina (n. ${ }^{\circ} 89$ ), amen de la consabida temática religiosa cultivada por su padre. Da cabida a los grabadores, siendo la producción más significativa al respecto los dibujos de Andrés Laguna en el libro de Bernardo Robredo Dilvcidacion nveva, y estvdiosa de las singulares virtvdes, y maravillosos efectos de la mamdragora (1646), a pesar de lo cual es ignorado por Vicente Barrantes ${ }^{17} \mathrm{y}$ citado muy lacónicamente por Escudero y Perosso. Con el nieto Francisco At ${ }^{\circ}$ de Cea y Paniagua daría fin la dinastía definitivamente en 1703, no sin dejar su huella en la fundación de una capellanía - «caso tal ves único en la historia tipográfica'» según Valdenebro-, sobre la que volveremos a tener noticias en 1766 en la persona de D. Antonio del Hoyo.

Sencillez y uniformidad temática marcan la obra de Andrés Barrera (1596-1603), que sería continuado otros diez y nueve años más por su viuda, ignorada por Barrantes, pero el simple hecho de que de sus prensas saliera, y a su costa, la 1. ${ }^{a}$ edición de la Historia General del Perv (1617), del Inca Garcilaso, habla no sólo del esfuerzo considerable que debió suponer para este modesto taller, sino la perspicacia de su regente al decidirse a publicar obra tan significativa.

Polifacético en sus impresiones se muestra también Andrés Carrillo de Paniagua (1636-1673) con los libros sobre fiestas en honor del Smo. Sacramento (1636), Medicina -Methodo curativo y vso de la nieve (1640), de Alonso de Burgos; Sobre la esencia del Morbo Gallico (1664) de Antonio de Bonilla Samaniego; manifiestos (1652), apologías -Vida y virtvdes del Venerable P. Varon el P. Cosme Muñoz (16549, del P. Luis de Mercado 
y Solís, autos de fe (1665) y la consabida temática religiosa. Sería continuado por su viuda durante muy breve tiempo (1673-1678) en lo que parece ser cerrar el trabajo comprometido en vida de su esposo.

La transición de siglos la protagonizarán Diego de Valverde y Leyva y Acisclo Cortés de Ribera (1684-1706), quienes debieron comprar en sociedad la imprenta al último de los Cea y pasarse dos años preparando y organizando el taller puesto que su primer impreso no llega a ver la luz hasta 1686. La oficina tipográfica cambiaría de nombre en dos ocasiones, la primera en 1701 en que se titularía «del eminentísimo Sr. Cardenal Arzobispo de Córdoba» y a la muerte de éste (el Cardenal Salazar), «de la Dignidad Episcopal».

La pobreza y simplicidad tipográfica siguen caracterizando a la producción cordobesa del siglo XVIII y muy raramente pueden encontrarse impresiones que se conviertan en excepción de lo dicho. Bien es verdad que el siglo XVIII dará entrada a una nueva etapa; libreros e impresores comienzan a marcar sus respectivos territorios y no es infrecuente encontrar que en el negocio de la imprenta las figuras del titular que gestiona y la de quienes en su labor profesional se convierten en "regentes» de los talleres, empiezan a estar separadas: podemos verlo en la Imprenta del Convento de San Agustín o Imprenta Agustiniana (1701-1716), la de Juan Ortega y Leon (1727-1738), la de Gonzalo Antonio Serrano, médico y astrónomo (1730-1755), que llegó a contar con 13 regentes mientras tuvo actividad, la muy prolífica del Colegio de la Asunción (1730-1767) que daría fin prácticamente en el momento mismo de la expulsión de los jesuitas, ya que los intentos posteriores de reorganización se verían definitivamente abortados en el motín de 1814, que "destruyó los aparatos y desperdigó por calles y plazas los moldes y letras de un establecimiento más bien "non nato" que "redivivo"». Igual procedimiento siguieron prácticamente todas las demás imprentas, de las cuales destacaremos por su continuidad y trascendencia posterior la fundada por - Diego Luis García Rodríguez, quien junto con Juan Crespo la había adquirido por traspaso al presbítero Simón Ortega y en la que en el siglo siguiente verían la luz las páginas del Diario de Córdoba. Otro de sus herederos, Juan Rodríguez de la Torre renovaría los tipos siguiendo el ejemplo de los grandes impresores de la época, especialmente de Antonio de Ibarra. Juan Rodríguez conseguiría el título de Impresor Real, siendo su trabajo más importante la segunda parte del Catálogo de los Obispos de Córdoba, de Juan Gómez Bravo (1778).

En el cambio de siglo hay que hablar de D. Luis de Ramos y Coria por su especial dedicación a la publicación de romances, estampas 
y pliegos sueltos, así como de algunos libros de corto número de páginas (1790-1823).

Entrado el siglo XIX ${ }^{19}$ y con las tropas napoleónicas ocupando la ciudad, están en funcionamiento las prensas de Rafael García Rodríguez y Cuenca, quien estampará sus pies de imprenta bajo el título de Imprenta Real salvo en los tres años constitucionales en los que pasará a denominarse Imprenta Nacional.

Digna de mención es la actividad de este taller en manos de su heredero D. Fausto García Tena (1844-1864), fundador del anteriormente citado Diario de Córdoba, el más duradero y emblemático de esta ciudad ${ }^{20}$. Amante de la literatura, a la que contribuyó con textos tanto en prosa como en verso, mejoró su taller tipográfico al que desde 1864 llamó Imprenta del Diario dotándole de los adelantos técnicos del momento, siendo el primero que incorporó a ellos la primera litografia. Su desaparición tendría lugar en el primer tercio del siglo XX (1938).

Importantes también fueron los talleres impresores de Rafael Arroyo, más tarde llamado Establecimiento Tipográfico Arroyo y Compañía (1853...); las Imprentas de la Alborada ( 1860-1862); El Eco ( 1869-1873) de D. Miguel José Ruiz; La Actividad (1873...), la Imprenta y Papelería Catalana (1884...); La Puritana (1888...); La Unión (1892...); La Región Andaluza (1894...) y La Verdad, que empezó trabajando en 1894 con las máquinas procedentes de la Imprenta de La Industria fundada por J . Baldomero Álamo en 1891.

Estas últimas imprentas de nombres tributarios de las nuevas ideas progresistas y revolucionarias a la vez que del naciente asociacionismo sindical, continuaron su actividad con mejor o peor fortuna en el siglo $\mathrm{XX}$. Pero ese es ya otro período.

A título anecdótico y para concluir este apartado, no debemos olvidarnos del pie de imprenta que figura en una obrita de 1813 y que dice haber sido impresa en Córdoba por Juan Pitard. Valdenebro no duda en mantener la inexistencia de este taller, considerando clandestina esta edición cuyo origen probablemente estuviera en Madrid (p. XXVIII).

No fueron prolíficas estas imprentas, según vemos al repasar el volumen de lo por ellas publicado. Esto es lo que hace exclamar a su mejor conocedor hasta la fecha, Valdenebro: «Aunque siempre hubo pocas imprentas en Córdoba, sorprende el que pudieran sostenerse haciendo el número relativamente corto de libros que se encuentran impresos en ellas, y es de creer, como dice mi sabio y bondadoso amigo Don Francisco de Borja Pavón, que 'darían materia de trabajo á sus talleres los muchos conventos, con anuncio de fiestas, cartas de her- 
mandad y programas de conclusiones; el Obispo y la Catedral, con edictos y tablas de predicación, y el Corregidor, con bandos, circulares, estados y Reales Cédulas» (p. XII), cuestión esta que nos remite, además, al tipo de lectores a quienes iban dirigidas estas publicaciones y de quienes trataremos más adelante.

\section{Otros profesionales: los grabadores}

Desde el comienzo de la imprenta, el grabado estuvo intrínsecamente unido al nuevo arte que venía a heredar la estructura y los procedimientos del códice manuscrito, siendo fiel a los objetivos perseguidos por la miniatura: no sólo adornar sino también ilustrar: «[su influencia] fue considerable desde su aparición y el nuevo arte se hizo inmediatamente popular, porque su producción numerosa, puesta al servicio de las creencias religiosas, de las ideas políticas, de las conveniencias económicas y de las pasiones sociales, le hacían asequible a los gustos y a las posibilidades de las gentes humildes que nunca hasta entonces habían podido disfrutar individualmente de los beneficios del Arte, el cual pasó a ser, por medio del grabado, como maravilloso elemento de vulgarización cultural, el admirable instrumento educativo de las multitudes ${ }^{21}$. En España, la historia del grabado va necesariamente unida a la de la tipografía, no sólo por el hecho de ser los libros quienes mejor han hecho llegar hasta nosotros gran cantidad de grabados, sino también porque los impresores y libreros intervinieron junto con los grabadores propiamente dichos a la difusión de este arte. Xilografias primero y calcografías y litografías más tarde, se vendrían a mezclar con la letrería y los varios alfabetos que surtían las imprentas. Bien es verdad que retratos, estampas o láminas exentas sólo tuvieron cabida en obras de cierto relieve o pretensiones y de costo más elevado, por lo que muy pocos talleres llegaron a contar con grabadores a su servicio, antes bien, se sabe que la comercialización de grabados desde centros especializados en Valencia, Barcelona y Madrid, a los que habría que añadir Sevilla y Granada en Andalucía, habían adquirido carta de naturaleza y prestigio suficiente, y era a ellos adonde se dirigían los talleres más modestos cuando de realzar sus impresiones se trataba con la incorporación de calcografías o litografías.

Dada la modestia de la imprenta cordobesa de la que repetidamente venimos hablando, son escasos los libros que incorporan abundancia de ilustraciones, por ello es más sorprendente encontrar el nombre de Gregorio Forstman -flamenco o madrileño según nos inclinemos 
por Ceán Bermúdez o por Viñaza ${ }^{23}$ - en dos grabados del libro del P. Posadas Vida y Virtudes del Uenerable Siervo de Dios el P. Christobal de Santa Catalina (1699), fechado en 1691 en Madrid; este grabador aún vería reproducida en el siglo XVIII una de sus planchas con la efigie de Jesús Nazareno en unas Reglas y Constituciones de la orden en 1740 y 1760 y en una biografía de P. Cristóbal de Santa Catalina en 1764. Un grabado de Esteban de Arteaga, impresor sevillano, realizado en Sevilla en $169 . .$. , se recoge en unos comentarios de Egidio Columna (1703), Algún grabado de Fr. Juan de Góngora —en el Méthodo curativo y uso de la nieve, de Alonso de Burgos-, de Diego de Leon -en el Tratado apologetico, de Diego de Mercado y Solís-. Interesantes también los del médico Andrés Laguna (1554-1586) reproducidos casi un siglo después en la obra de Bernardino de Robredo sobre los Efectos $y$ virtudes de la mandrágora (1646).

Nuevos nombres aparecen en el siglo XVIII: Vela graba un escudo de armas del mecenas de la tercera edición de los Comentarios de E. Columna en 1712; el conocido pintor cordobés Antonio Palomino grabaría en Madrid un Santo Tomás de Villanueva para una obra del P. Siuri (1727); Io. Petroschi un mapa de la Provincia del Chaco y colindantes (1733) en la obra ya citada de Pedro Lozano; Nicolás Carrasco, grabador del círculo de Juan Bernabé Palomino, es el autor del grabado de San Rafael realizado en Córdoba en 1732 que aparece en un texto de Pedro de Sylva en 1736; Juan Díez, discípulo igualmente de Palomino, es autor de escudos de armas (1760), de un retrato del P. Juan de Santiago en 1763 en una biografia cuyo autor es el P. Vicente Morales y otro en una edición póstuma de sus obras en 1765; del túmulo de las honras del mismo J. de Santiago en 1764; otro retrato del V. Gregorio Lopez (1736) en una obra colectiva en pro de su canonización; una Inmaculada y un San Rafael con el escudo del Colegio en unos Estatutos del Colegio de Abogados de Córdoba, en 1770. El nombre de Pedro Minguet aparece en un escudo de armas en 1767 y el de Juan Minguet en otro escudo de armas de la ciudad de Lucena en 1787. José Martínez graba en Córdoba una Inmaculada en 1773 para una obra de Manuel M. ${ }^{a}$ Truxillo, y Juan Ribades un escudo de armas nobiliario en 1779.

En el siglo XIX continúan las planchas calcográficas cuyos autores son José Sánchez - una Virgen de Linares, Córdoba, 1805-, Castro, sobre dibujo de Coronel, hace un retrato del P Posadas (1807); Bartolomé Vázquez «el único que puede competir con Palomino e incluso superarle» ${ }^{24}$, se ocupa de San Rafael (1807); José Santiago, de San Pedro (1814). Y la novedad surge en 1853 donde la Imprenta de D. Rafael Arroyo ha proporcionado una litografía que representa a un 
hombre y un caballo para la obra de Pedro A. Sartorius Manual de equitación - recordemos que la litografia fue introducida en España el año 1818, a partir del cual se convertirá en el sistema de ilustración característico de los dos primeros tercios del siglo XIX. Otra litografía de González para un retrato de Rafael Molina Lagartijo en Toreros cordobeses de José Pérez de Guzmán (1870); diez litografías de figuritas astronómicas salidas de la litografia del Diario de Córdoba, para la obra de Joaquín Montero Anuario geográfico-astronómico y cronológico para el año de 1878 (1878); otra litografia de una reproducción de la Carta-Fuero concedida a Córdoba, en edición de 1881. Y por último, tras láminas grabadas en madera e intercaladas en el texto para ilustrar un libro de instrucciones sobre máquinas trilladoras (1882).

$\mathrm{Ni}$ que decir tiene que en todo este tiempo no han desaparecido los tacos de madera que ilustran escudos religiosos, alguna figura de virgen o santo, capitales, guirnaldas, orlas, culs de lamp, florones y otros elementos ornamentales que ocupan cabeceras y finales de página sin más afán que evitar el mero horror vacui o para dar un poco de ambientación al tema cuando de pliegos sueltos se trata.

\section{Temas}

En los siglos XVI y XVII predominan los temas de carácter religioso: sermones, dilucidaciones apologéticas, liturgia, reglas constituciones, villancicos, etc. Quizá su cuantificación no sirva de indicador absoluto y fiel del gusto de los lectores, pero sí de la especialización de ciertos impresores y de los intereses de instituciones determinadas - conventos en su mayoría - que formaban sus bibliotecas de acuerdo con orientaciones precisas emanadas de la autoridad eclesiástica, especialmente a partir de Trento, y con fines definidos, como podrían ser, de una parte, el enriquecimiento espiritual de los hermanos en religión y el que éstos pudieran transmitir ese enriquecimiento y perfeccionamiento a sus feligreses; de otra, el conocimiento de unas leyes que presuponen la existencia de derechos y deberes por los que regirse. La redacción de índices temáticos mostraría la desproporción existente estre unos temas y otros, así como la presencia esporádica y fortuita de algunos de los que se conoce un sólo ejemplar. No faltan sin embargo muestras de historia local -Antigvo principado de Cordoba, del P. Martín de Roa (1636)_, nacional —Origen y primeras poblaciones de España, del P. Juan Felix Giron (1686) - o universal — la ya citada Historia General del Perv del Inca Garcilaso (1617). Con cuentagotas aparece 
el tema médico - Methodo curativo y vso de la nieve (1640) y Tratado de la peste (1651) ambos del médico Alonso de Burgos; la también citada Dilucidacion nveva y estvdiosa de las singulares virtudes y maravillosos efectos de la mandragora (1640); Desengaño del mal uso del tabaco (1634) del Dr. Francisco de Leiva Aguilar: Sobre la esencia del Morbo Gallico (1664), de Antonio Bonilla Samaniego y algunos más; las relaciones de fiestas, casos curiosos, biografías, derecho e, incluso, la relación del Auto de Fe que se celebró en esta ciudad en 1665.

La Literatura, entendida ampliamente, se interesa por el género biográfico, centrada en la vida de religiosos ilustres, entre los que destacan las varias ediciones que se sucedieron en la centuria dieciochesca sobre el célebre orador, persecutor incansable de las representaciones teatrales, el P. Francisco Posadas. No faltan tampoco biografias femeninas de damas y monjas ejemplares. Las Fiestas, tanto de carácter civil como religioso, dieron lugar a variadas publicaciones, entre las más conocidas las celebradas en el siglo XVII con motivo de la beatificación de la Madre Teresa de Jesús en 1615 y recopilada y publicada en 1616 por Páez de Valenzuela, sin que falten otras dedicadas a conmemorar nacimientos principescos o defunciones reales -Naratiba funebre, tristes, y lvgubres lutos, en la muerte del Rey Don Phelipe Quarto el Grande... (1665), por Francisco Diaz Cano-. El gongorino Miguel Colodrero de Villalobos saca en las prensas unas Rimas (1629) y debe ser anotada como algo excepcional la edición de Quatro comedias de diversos autores (una de Góngora, dos de Lope y otra anónima), recopiladas por Antonio Sánchez en 1613.

Más variados, aunque continuadores de los precedentes, encontramos en el siglo XVIII La Historia General de Córdoba del P. Francisco Ruano (1761) de la que sólo se imprimió el primer tomo; el Opvsculo [...] que prueva, que todos los carbuncos son malignos... (1702), de Gonzalo Antonio Serrano. Muy escasos también resultan ser los de Geografía -Descripcion chorographica del terreno, rios, arboles y Animales de las dilatadissimas Provincias del Gran Chaco, Gualamba: y de los ritos, y costumbres de las innumerables Naciones barbaras, e infieles, que le habitan..., (1733), por Pedro Lozano-, más atraídos por la Astrología, acompañados de Tablas y Pronósticos varios que aparecen con periodicidad anual; y en general ciencias como la Geometría o las Matemáticas que van haciéndose presentes en la imprenta cordobesa sobre todo a partir del siglo XVIII.

Más proclive se muestra la imprenta cordobesa dieciochesca con el género teatral -Eufemia ó el triunfo de la Religion (1775) drama 
traducido del francés y prohibido por la Inquisición española en 1805, la comedia heroica Mohamed Boabdil (1787), las Máscaras que tendrían lugar en Córdoba con motivo de la exaltación de Carlos IV (1789)... También se publicaron opúsculos en los que se atacaba duramente a las representaciones dramáticas -Abvso diabolico de celebrar con representaciones comicas el santo Nacimiento de Nvestro Redemptor... (1716), obra de un anónimo fraile jerónimo...

Pero sin lugar a dudas, lo que más trabajo dio a las prensas en este siglo fue la publicación de los llamados "papeles menores», entre los que sin lugar a dudas sobresalen los Villancicos que se han de cantar en la Santa Iglesia Catedral; los romances y pliegos sueltos sobre los más diversos temas; las novenas, setenarios, bulas, reglas y constituciones, pronósticos y algún que otro auto de fe.

Hasta sesenta entradas más recoge Valdenebro sin fechar si bien todas atribuibles al siglo XVIII, a juzgar por los pies de imprenta y las características tipográficas ${ }^{25}$ : romances sagrados y profanos, novenas, relaciones, pliegos de oraciones varias... de dos hojas sin foliar, forman este conjunto, indudablemente destinado y consumido por lectores poco exigentes e indudablemente más numeroso que el de los sermones, historias y tratados de intención más erudita y alcance más reducido.

El siglo XIX, a partir de 1808 y mientras dura la invasión napoleónica, va a introducir un nuevo tipo de publicaciones, en las que franceses, afrancesados y autoridades galas serán denostadas frente a la exaltación patriótica de la que suelen hacer gala estos papeles que no llegan a alcanzar tampoco amplio número de páginas. La excepción a la temática antifrancesa la constituye la Oda laudatoria que Manuel M. a de Arjona dedicó a la coronación de José Bonaparte I, de la que luego habría de arrepentirse, y que fue impresa en La Imprenta Real en 1810.

Más agitada la sociedad cordobesa en la primera mitad del siglo XIX, abundan las publicaciones de Reales Cédulas mediante las cuales se pretende dar publicidad a las normas que habrían de regular la vida de los ciudadanos: ordenamientos jurídicos territoriales, censura de libros y papeles, leyes desamortizadoras y de reversión de bienes, manifiestos a la nación, etc. etc. junto a textos fuertemente politizados, dan un nuevo aire a las prensas cordobesas, sin por ello abandonar los ya tradicionales ataques a las representaciones teatrales -Discurso politico-moral contra el teatro (1813); Destierro de las comedias de la ciudad de Córdoba en 1694 por acuerdo de su ilustre Ayuntamiento á instancias del V.P. Presentado Fr. Francisco de Posadas [...] y la 
prohibicion de las mismas en todo este Obispado por el Sr. D. Carlos III, en 1784 ... (1824); villancicos, sermones, novelas y otros papeles devotos.

Con la llegada de Isabel II al trono, Córdoba ha recorrido un camino similar al del resto de la nación; en lo que hace a los temas que nutren las publicaciones, se advierte un notorio descenso del género oratorio de carácter religioso; perviven las composiciones populares por medio de los citados villancicos, y junto a textos jurídicos, las matemáticas, geografía, gramáticas, libros sobre agricultura, filosofía, higiene... demuestran si bien tímidamente que la Ilustración ha conseguido introducir sus luces en este rincón en el que no faltan traducciones como la Enciclopedia de la juventud o compendio de las Ciencias y Artes (1840), por la condesa de Hautpoul. De mediados de siglo data la Corografia Histórico-Estadística de la provincia y Obispado de Córdoba (1840), una de las obras pioneras de la historiografía local, y el Indicador cordobés, o sea, Manual histórico-topográfico de la ciudad de Córdoba (1856), por D. Luis M. ${ }^{a}$ Ramírez de las Casas-Deza, ambas de indiscutible valor científico. Con ellas puede decirse que las puertas de la imprenta cordobesa se han abierto a la modernidad con una temática ya definitivamente secularizada en estos años a diferencia de lo que sucedía en los que les precedieron: Todos los temas en mayor o menor medida han terminado por hacer su aparición y los nombres de sus autores han pasado en muchos casos a formar parte del acervo de la literatura local.

Y como en el siglo XVIII, los papeles sin foliación y reducido número de páginas, contraponen unas publicaciones -105 en total, a los que habría que sumar las trescientas «hojas volantes» de D. Luis de Ramos y Coria y las trescientas de D. Rafael Rodríguez-, de carácter popular, volandero y de consumo que se mueven entre la devoción y el divertimento como venimos diciendo.

\section{Lectura y lectores}

Repetidamente venimos aludiendo a la posibilidad de que la producción impresora cordobesa y los temas que recogían estuvieran directamente relacionados con encargos concretos y gustos de los lectores; ahora bien, cuando nos referimos sin más a la práctica de la lectura, el campo se abre a la producción libresca que procede de fuera, mucho más rica sin duda no sólo en número de títulos sino también en temas. Para iniciar una aproximación, pues, al fenómeno que nos ocupa será 
necesario delimitar en primer lugar unas esferas de actuación en torno a lo que serían: a) lecturas del clero tanto regular como secular; b) lecturas de los fieles en cuanto tales, y c) lecturas de analfabetos. Y en segunda instancia habría que delimitar los distintos tipos de lectura: a) Biblia, Misales, textos doctrinales y Catecismos; b) académicas o cultas y c) lecturas populares ${ }^{26}$.

En cuanto a las lecturas del clero en Córdoba puede tenerse una idea bastante aproximada con sólo asomarse a los fondos de la Biblioteca Episcopal y al fichero del fondo antiguo de la Biblioteca Pública del Estado o a su Catálogo ${ }^{27}$, procedentes como advertimos más arriba de fondos desamortizados, notoriamente menguados primeramente por causa de los saqueos y vandalismo generalizado de las tropas invasoras francesas y más tarde en las gruerras entre cristinos y carlistas ${ }^{28}$ en su traslado a diversas ubicaciones provisionales, si atendemos a lo que reseñan los inventarios desamortizadores conservados ${ }^{29}$, pero que ofrecen una visión de conjunto acerca de cuáles fueron los intereses lectores de los religiosos hasta el primer tercio del siglo XIX. La reconstrucción pormenorizada de lo que ha llegado hasta nosotros de Conventos y Monasterios, a partir de los títulos de propiedad consignado en portadas, guardas o páginas iniciales y finales, está redactado en parte ${ }^{30}$. En general puede afirmarse que no falta materia de relevancia en este corpus bibliográfico - a pesar de que como apunta Antonio Flores «las comunidades religiosas debieron poner a salvo aquellos fondos que, por su importancia bibliográfica o temática y necesidad de uso, estimaran convenientes. La cesión de libros a deudos y allegados debió ser numerosa. El resto quedó en las sedes conventuales, donde debió sufrir abundantes pérdidas, dada la lentitud con que se procedió a la recogida»-, si bien el peso mayor de los libros conservados recaiga sobre los temas de apologética, teología, espiritualidad, formación catequética, filosofia, derecho en su vertiente canónica y civil, no se olvide que religiosos y sacerdotes ostentaban la dirección espiritual de los fieles y que el conocimiento de la doctrina sagrada junto con la obligación de divulgarla y de formar conciencias impuesto por Trento, obligaba al estudio intensivo de las grandes obras recomendadas por las autoridades eclesiásticas. Así pues, las bibliotecas conventuales debían contar inexcusablemente entre otros con el catecismo romano $y$ el de Pedro Canisio, así como de Manuales para confesores, el Enchiridion de Martín de Azpilicueta; comentarios y homilías de los Padres de la Iglesia sobre las Escrituras (S Agustín, S. Juan Crisóstomo, S. Gregorio...), los comentarios a la Summa de Sto. Tomás de Aquino, todas ellas en los fondos conventuales cordobeses citados al igual que 
entre los fondos del Colegio de la Asunción, o las obras de controversia antiprotestante. Entre 1650 y 1730 se añadieron a éstas Instruction du Chrétien, de Armand du Plessis de Richelieu, los decretos del concilio de Trento, comentarios sobre las Morales y el Libro Pastoral de S. Gregorio, textos de teología moral; lecturas espirituales como la Inmitación de Christo de Thomás de Kempis, la Guía de pecadores de Fr. Luis de Granada, la Introduccion a la vida devota, de San Francisco de Sales... Pero estos lectores no reducían su interés a los temas meramente religiosos y así, las nuevas corrientes filosóficas y científicas irrumpieron en las estanterías de las bibliotecas aludidas con igual interés que las obras anteriores: Obras de los novatores -1680-1724 según J.L. Abellán-y sus precursores -Juan Caramuel y Libkowitzestán presentes en mayor o menor medida eludiendo en lo posible problemas con la cultura oficial ${ }^{31}$. Las Controversias de León de Castro contra Arias Montano sobre las Sagradas Escrituras así como las obras de éste último y las de Melchor Cano, están ampliamente representadas en los fondos conventuales citados; lo mismo sucede con Domingo Báñez y Luis de Molina, enfrentados en sus disputas teológicas; con las obras de Jansenius y otras muchas en torno a la definición de la concepción de María, y aquí entrarán también los nombres de Domingo de Soto y los de otros que derivarán por otras disputas teológico-políticas y jurídicas.

Autores místicos como Santa Teresa de Jesús, San Juan de la Cruz, especialmente en ediciones del siglo XVIII, Santa Catalina de Siena, sor María Jesús de Agreda... ocuparán igualmente un lugar nada desdeñable entre estas posibles lecturas al igual que otros libros contra los protestantes, como los de Alfonso de Virués.

La Filosofía está representada por Aristóteles, Cicerón, Plutarco, Quintiliano... entre los antiguos; Domingo de Soto, Francisco Suárez, el P. Mariana, Gracián, Saavedra Fajardo... entre los más recientes. Las Ciencias -Matemáticas, Ciencias Naturales-, por Sebastián Izquierdo y Atanasio Kircher. La Metafísica por Justo Lipsio y Séneca. El Derecho ofrece una extensa panoplia: allegaciones jurídicas, consejos, leyes, constituciones, «porcones»... nutren los volúmenes de «varios» y repiten fórmulas y diatribas. La Medicina de Hipócrates y la que más tarde enfrentó a galenistas contra los seguidores de Harvey también dejó su fruto con las obras de Juan de Torres y Valcárcel.

Alquimia, Astrología y Magia, pese al control inquisitorial, se mezclan en las obras de Pedro Ciruelo o Juan Eusebio Nieremberg. Otros muchos nombres y obras enriquecen estos fondos junto a libros de Historia -P. Mariana, Zurita...-, Crónicas — de Francisco Rades y 
Andrada-, Geografía -Ptolomeo en lugar preeminente, Juan de Sacrobusco - entre otros más nos sitúan ante la posibilidad de contar con lectores interesados y al día de las corrientes ideológicas que se debatían en ese momento dentro y fuera de España.

Como apunta Dominique Julia «El inmenso esfuerzo pedagógico de la Contrarreforma iba encaminado a hacer que los miembros del clero parroquial fueran hombres de estudio y de libros» ${ }^{32}$. Como consecuencia de lo anterior, y con el transcurso de los años fueron naciendo nuevos manuales de teología, sermonarios - de Alonso de Villegas, Alonso de Cabrera, Barcia Zambrana, Pizaño de Palacios, P. Posadas-, guías para confesores -Melchor Cano-, etc, que completaban los fondos de estas bibliotecas a las que sus miembros podían acceder directamente y cuya lectura queda a veces reflejada en los subrayados y anotaciones manuscritas que conservan los volúmenes, algunas simplemente alusivas al permiso otorgado al lector para poder llevar el libro a su celda durante algún tiempo ${ }^{33}$.

b) Las lecturas de los fieles cordobeses son mucho más difíciles de detectar, puesto que habría que contar bien con información obtenida a partir de inventarios post mortem —en lo que se está trabajando-, bien de confesiones personales en cartas o biografías de las que carecemos por el momento. Hay que suponer un aumento tanto de lectores como de lecturas entre los siglos XVI y XVIII como consecuencia de una escolarización creciente y de las mayores facilidades para el acceso a la cultura. Posiblemente también sería necesario distinguir entre las lecturas de escolares obligadas a los estudiantes del Colegio de la Asunción regentado por jesuitas, cuyas muestras podemos rastrear en los fondos conservados de su biblioteca y que coinciden en gran medida con los conventuales - el P. Señeri, por ejemplo- con la excepción de ser más variada y actualizada especialmente en materias profanas como la Lengua y la Literatura: el Diccionario de Nebrija, las obras más significativas de Antonio de Guevara, de Fr. Luis de Granada, Virgilio, Carrillo de Sotomayor, Los Comentarios Reales del Inca Garcilaso, las Fiestas de la Torre Farfán, las Rimas de Tomé de Burguillos, etc., obras de Góngora, e, incluso, unas muy apropiadas Reglas de Politica Moral, y Civil para instruccion de los Cavalleros Colegiales del Real, e lnsigne Colegio de Nuestra Señora de la Asumpcion de Cordova por Don Luis de Ramos y Coria. Las de algunos individuos pertenecientes a las casas nobiliarias y por último las lecturas del pueblo llano, más cercano, suponemos al mundo de las Relaciones y Romances además de las obligadas lecturas formativas desde el punto de vista religioso. 
c) Las lecturas de los analfabetos hay que suponerlas en el nivel de «lectura oída» de que nos habla Margit Frenk, que si bien no excluye la temática religiosa de milagros, oraciones, novenas, catecismos, etc. más bien giraría en torno a los contenidos propios de las hojas volanderas y los pliegos sueltos, con lo que salimos de lo que hemos venido en llamar «esferas de actuación» para entrar en los «tipos de lectura».

A este respecto, no es baldía la advertencia de Roger Chartier sobre el hecho de que sería más oportuno hablar de «lecturas compartidas» que de "tipos de lectura» en función de los lectores, como han puesto de manifiesto para el caso de España los interrogatorios inquisitoriales, pues lo que caracteriza a un lector no es «el corpus de sus lecturas, sino su manera de leer, comprender y utilizar al servicio de una cosmología original los textos a los que se tenía acceso» ${ }^{34}$. La forma de apropiación de un texto puede convertirlo en popular aunque su origen sea culto y la manera de hacerlo no siempre pasa por el desciframiento de un código escrito, por lo que la inclusión de «lectores analfabetos» en los círculos de lectura culta no fueron tan anómalos como pudiera parecerlo entre los siglos XVI y XVIII. Las estrategias editoriales irían perfilando distintas formas de acceso a la lectura para personas cultas e instruidas por medio de sus bibliotecas privadas cuando existen; para los iletrados no han quedado rastros que puedan sernos de utilidad para el caso específico cordobés salvo las imprentas citadas en páginas anteriores, dedicadas muy intensamente a la producción y comercialización de pliegos sueltos.

En el siglo XVIII, Córdoba - al igual que gran parte de Españadebió permanecer lejos de la "revolución lectora» que afectó especialmente a Europa central, Francia e Inglaterra. Sí puede afirmarse que progresivamente debió pasarse de una «lectura intensiva» según el canon aceptado, a una «lectura extensiva» por la que se populariza el libro: «...la lectura repetitiva [...] se ve sustituida por un comportamiento lector extensivo que pone de manifiesto de un modo moderno, laicalizado e individual, cierta avidez por consumir un material nuevo, más variado $y$, en particular, por satisfacer el deseo de entretenerse privadamente» ${ }^{35}$. Hay que suponer que el incremento de los lectores en Córdoba no debió ser muy significativo con respecto al siglo anterior pues el carácter rural de la nobleza ${ }^{36}$ al igual que el de las clases populares la alejaba de las inquietudes culturales que bullían en las clases burguesas de otros paises y que nacían con la conciencia de una exigencia de alfabetización masiva de los habitantes.

El abanico de posibilidades lectoras se abre con la inclusión de un público femenino y juvenil, el primero volcado especialmente hacia 
novelas de entretenimiento y el segundo combinando las lecturas intensivas, propias de sus actividades estudiantiles, con las extensivas, hacia las que se volcaban sus gustos personales.

$\mathrm{El}$ arrinconamiento progresivo del latín como lengua de cultura, iniciado en los siglos anteriores, da ahora un paso definitivo, ayudado posiblemente por esa masa media de lectores no ilustrados que buscan en la lectura la simple distracción. Simultáneamente el proceso de secularización de la sociedad hace retroceder la lectura religiosa a favor de materias consideradas más actuales: geografía, ciencias naturales, matemáticas, pedagogía... y literatura en general. Si nos atenemos a lo que publican las imprentas, los gustos siguen escindidos entre lectores cultos y lectores populares, pero no se pierda de vista la comunidad de lecturas a la que hicimos alusión más arriba.

El siglo XIX populariza el libro en España; la urbanización de la sociedad favorece la demanda de los lectores cuyo número y condición se amplían considerablemente y el desarrollo de la enseñanza solicita la publicación de libros de texto y de consulta, a lo que ayuda el abaratamiento de los costes de producción al ser aplicados los modernos adelantos de la industria al mundo de la imprenta. Se inicia un aumento en la alfabetización sobre todo masculina -las mujeres españolas, especialmente las andaluzas, seguían ocupando desafortunadamente unos de los puestos más bajos en la escala de la alfabetización nacional ${ }^{37}$ - Se diversifica con ello la tipología de los lectores, ahora más amplia y variada en atención a gustos y niveles de instrucción: temas y libros para lectores cultos y para quienes no lo son tanto o sólo aspiran a distraerse; los primeros no habrían de rebasar los ámbitos académicos o intelectuales salvo aquellos que por especiales circunstancias del autor - las excelentes relaciones de Antonio Fernández Grilo con la Corte isabelina y los ambientes madrileños, entre los más sobresalientes-, o por su realidad científica - los de Ramírez de las CasasDeza-, consiguieran traspasar los límites provinciales. No así las hojas volantes y pliegos sueltos que desde los talleres cordobeses circularían por esquinas y plazas de los pueblos de España, unas veces para ser cantados por los ciegos, otras para leídos en privado al amor de la lumbre o la soledad de las habitaciones para solazar a los oyentes o lectores con los amores de las romanceadas comedias famosas, rezar al santo de la devoción particular o sobrecogerse con los terribles crímenes de bandidos como Cintas Beldes. Literatura en parte proveniente del siglo XVIII, pero reeditada una y otra vez ante la masiva demanda de que era objeto desde cualquier parte de España, atraídos unos y 
otros por el andalucismo violento y el tomo vulgar y generalmente de pésimo gusto que parece ser que atraía a «gente pobre, comúnmente analfabeta, para quienes los versos del ciego cantor eran el único escape a la fantasía» ${ }^{38}$. Por otra parte, parece que fue en ellos donde iniciaron las primeras letras la mayoría de los escasos españoles que por entonces accedían a ella, hasta que se contó con un único texto oficial en 1826: El arte de hablar, de Hermosilla ${ }^{39}$.

$\mathrm{Y}$ aunque siempre moviéndonos sobre hipótesis, dos documentos pueden ser traidos a colación como muestra del acceso a la lectura de grupos sociales cordobeses que en el transcurso del siglo van adquiriendo personalidad propia: las mujeres y las clases obreras campesinas marginadas. Sírvanos de base el escrito biográfico de $\mathrm{D}^{\mathrm{a}}$ Catalina Manzano ${ }^{40}$ primero y la novela de Manuel Ruiz-Maya Los libertadores del campo después.

En el primer caso, la educación de las mujeres de clases burguesas incrementó las posibilidades lectoras que, como en el caso que nos ocupa y que puede considerarse antológico, oscilaba entre las «lecturas canónicas» -Evangelio en triunfo, Poemas cristianos, Concilio de Trento...- y las novedades literarias especialmente novelas traducidas — La Atala, El Judío Errante, Los misterios de París, Nuestra Señora de París y muchas novelas de Dumas de quien dice haber olvidado los títulos ${ }^{41}$ - . La dificultad de dirigir y seleccionar las lecturas propias hacen que a esta Doña Catalina Manzano no pueda aplicársele la opinión de Stendhal sobre que la femme de chambre lee autores como Paul de Kock mientras que la femme de salons prefiera la novela en octavo, más respetable, y que se precia de cierto mérito literario» ${ }^{42}$. D. ${ }^{\text {a }}$ Catalina - como tantas mujeres del siglo XIX - se subordina en sus lecturas a los gustos del padre ya que las mujeres no suelen figurar como propietarias de una biblioteca como tal, «sino de libros generalmente sueltos, heredados o confundidos entre las lecturas supuestamente masculinas» ${ }^{43}$ y reconoce que los libros le proporcionan un placer furtivo: «lei todos los libros de Papá pues que no tenía otros ni quien me los diera y por esto muchas veces leia sin entenderlos, pero a pesar de esto gozaba, pues que leer era mi único placer».

El segundo texto, dentro de la órbita de la lectura ideologizadora obrerista, sabemos que llegaba a amplios sectores de la población no ilustrada por medio de la tradicional lectura en voz alta en los escasos momentos de asueto ${ }^{44}$; público que no compra libros, pero que accede indiscriminadamente y por el mismo sistema a obras como la citada del mismo modo y por el mismo procedimiento que a La conquista del pan, de Kropohkin, Las Nacionalidades de Pi, las obras de Onésimo 
Reclus y tantas otras, movidos por el ansia de adquirir un saber sobre el que sentar las bases de la acción política.

$\mathrm{Y}$ junto a esta lectura silenciosa en el ámbito de la privacidad de un lado, y la lectura en voz alta en el campo de otro, el número de lectores que accedían a la Biblioteca Pública de Córdoba para leer según los documentos varía si repasamos los estadillos redactados por los directores a solicitud de las autoridades gubernativas:

1861: Abril: 35

Mayo: 33 septiembre: 38

Junio: 42

Octubre: 57

Julio: 41

Noviembre: 59

Diciembre: 30 (hasta el día 21 )

1862: Febrero: 14 (desde el día 21)

Marzo: 61

(Apéndice V: Parte trimestral, 1862, por Julio de Eguilaz; en Axerquía, n. ${ }^{\circ} 7$ ).

En otro lugar se cifra la asistencia de lectores en 5 ó 6 diarios y se viene a justificar la escasez de usuarios por las condiciones precarias en que está la biblioteca cordobesa:

Es tal la humedad y pútridos miasmas de que se halla cargada la atmósfera de dichas salas, que no es posible estar sometido á ella mucho tiempo impunemente: Así viene ocurriendo que las personas robustas enfermas, las delicadas sucumben y los libros se deterioran hasta el punto de pudrirse muchos de los que ocupan las tablas próximas al suelo. La temperatura que se disfruta, mejor dicho, que se padece, es también, salvo en algunos días, de primavera, molesta en sumo grado, pues si sofocante resulta en verano por hallarse el local bañado por el sol todo el día, peligrosa e insufrible resulta en invierno, por lo bajas observanse que, aún en los días más crudos, el ambiente exterior resulta templado al salir a él. Seria inútil añadir que esto ahuyenta a los lectores, dificultando uno de los principales fines de esta clase de Establecimiento (la cursiva es nuestra). (Apéndice XVI, $p$ 30).

Otro público lector sin duda es el que acude a la recientemente por entonces fundada Real Academia de Córdoba, de Ciencias, Bellas Letras y Nobles Artes, fundada por D. Manuel M. ${ }^{a}$ de Arjona en 1810, y el que en el Liceo se reúne para entretenerse con la prensa y los libros de su no despreciable biblioteca. Habría que hablar incluso de la aparición de bibliófilos como Argote-Cabriñana, Ramírez de las Casas-Deza y otros más humildes pero no por ello menos conocedores en materia y gustos bibliofílicos como Francisco de Borja Pavón, parte de cuyas bibliotecas fueron igualmente donadas a la Biblioteca Provincial de Córdoba ${ }^{45}$, ponen de manifiesto un interés específico por 
la lectura personalizada en pequeños grupos dentro de los ambientes aristocráticos o pequeño-burgueses que formaron parte del entramado culto de una sociedad no demasiado brillante por estos años en la república de las letras. Un estudio más pormenorizado que el que aquí se aborda habrá de poner orden y cifras sobre el particular. Baste con reconocer y advertir de su existencia.

El siglo XX continuaría en principio en Córdoba la tradición impresora anterior, pero su faz va a ir cambiando a la par que tras las dos guerras mundiales lo hiciera el mercado editorial europeo: muchos de los pequeños talleres fueron desapareciendo para mantenerse los que quedaron con producciones meramente utilitarias o propagandísticas. La concentración editorial acaparará el mercado del libro y sólo las instituciones civiles o académicas mantendrán una producción libresca más o menos regular, con frecuencia de un estimable nivel científico, escasamente bien distribuida, pero siempre de indudables connotaciones localistas. Con ellas no obstante será preciso contar a la hora de hacer una más fiel historia del libro y la cultura cordobesa del siglo que está a punto de concluir.

\section{Notas}

1400.000 ejemplares según historiadores arabes como Al-Maqqari o Ibn Jaldún quienes hablan de un catálogo de cuarenta y cuatro cuadernillos de cincuenta folios cada uno hasta su venta parcial primero y saqueo después. Cfr. Ramón Menéndez PidaL: Historia de España. T. IV, p. 471: España Musulmana hasta la caída del Califato de Córdoba, por E. Lévi-Provençal. Madrid, Espasa-Calpe, 1976 y T. V: España Musulmana Instituciones y vida social e intelectual, por E. Lévi-Provençal. Madrid, Espasa-Calpe, 1965.

2 Aguilar Gavilán, Enrique: Córdoba en el pasado. Breve historia de una ciudad Patrimonio de la Humanidad. Córdoba, Ayuntamiento, eds. La Posada, 1999.

3 Ribera, Julián: La enseñanza entre los musulmanes españoles. Bibliófilos y bibliotecas en la España musulmana. Córdoba, Imp. La Comercial, 1925 (3 ${ }^{\mathrm{a}}$ ed.).

4 Berger, Philippe: Libro y lectura en la Valencia del Renacimiento. Valencia, Eds. Alfons el Magnánim, Institució Valenciana d'Estudis i Investigació, 1987; Ángel Weruaga Prieto: Libros y lectura en Salamanca: Del barroco a la Ilustración (1650-1725). Valladolid, Consejería de Cultura y Turismo, 1993, J. Cerdá Díaz: Libros y lectura en la Lorca del siglo XVII. Murcia, Caja de Murcia, 1986; Jesús Martínez Martín: Lectura y lectores en el Madrid del siglo XIX. Madrid, C.S.I.C., 1991.

5 Córdoba Conventos. Inventario n..$^{\circ}$. Archivo General del Obispado de Córdoba y Porro Herrera, M. ${ }^{a}$ José: «La Biblioteca Pública Provincial de Córdoba. II. Procedencia de algunos volúmenes que integran su fondo bibliográfico antiguo", en Axerquia. Revista de Estudios Cordobeses, n. ${ }^{\circ}$, septiembre, 1983; pp. 9-42. 
6 Porro Herrera, M. a José: «La Biblioteca Pública Provincial de Córdoba. I Historia», en Axerquía. Revista de Estudios Cordobeses, n. ${ }^{\circ}$ 7, junio, 1983; pp. 9-34.

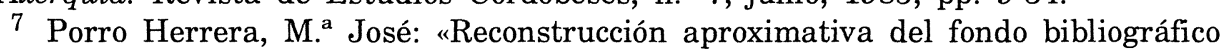
del Convento de Nuestra Señora de los Remedios, de Carmelitas Descalzos, de Benameji", en Trabajos de la Asociación Española de Bibliografía. I. Madrid, M. ${ }^{\circ}$ de Cultura / Biblioteca nacional, 1993; pp. 243-260.

8 Libros y lecturas de un poeta humanista. Fernando de Herrera. Ed. Ana Rojas y Pedro Ruiz. Córdoba.

9 Frenk, Margit: «Lectores y oidores: la difusión oral de la Literatura en el Siglo de Oro", Actas del VII Congreso de la A.I.H. T. I. Roma, Bulzzoni, pp. 101-123.

10 En Cuadernos del Sur. n. ${ }^{\circ}$ 57; Diario Córdoba, 3-III-1988, p. VI.

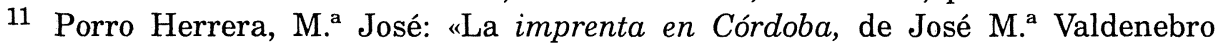
a la luz de la Tipobibliografla Española», en El libro antiguo español. Actas del segundo

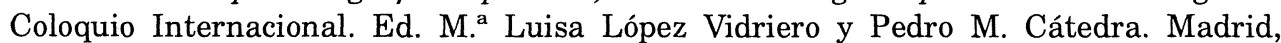
Univ. de Salamanca / Biblioteca Nacional / Sociedad Española de $\mathrm{H}^{\mathrm{a}}$ del Libro, 1992; pp. 367-398.

12 González Francés, Manuel: “Más datos sobre imprentas e impresores de Córdoba». Diario de Córdoba. 23 de septiembre de 1888.

13 Ramírez de Arellano, Rafael: Ensayo de un Catálogo Biográfico de escritores de la Provincia y Diócesis de Córdoba con descripclón de sus obras. Madrid, Tipogr. de la Revista de Archivos, Bibliotecas y Museos, 1922.

14 Rodríguez-Moñino, Antonio: La imprenta jerezana en los siglos XVI y XVII (1564-1699). Madrid, Impr. Sucesores de Sánchez Ocaña, 1942.

15 Aguilar Gavilán, Enrique: Córdoba en el pasado. Breve historia de una ciudad Patrimonio de la Humanidad. Córdoba, Ayuntamiento, eds. La Posada, 1999.

16 Cfr. José Gestosso y Pérez: Noticias inéditas de impresores sevillanos. Imp. de Gómez hermanos, Sevilla, 1924, p. 119 donde estudia a Juan Bautista Escudero.

17 Barrantes, Vicente: "Apuntes para un catálogo de impresores, desde la introducción del arte en Espana hasta el año de 16..", en Revista Contemporánea, T. XXVII, 1880 .

18 Francisco de Borja Pavón, apud Valdenebro, pp. XXIII-XXIV.

19 Ramírez de las Casas-Deza, Luis M.a: Biografía y Memorias especialmente literaria. de D. Luis María Ramírez de las Casas-Deza. Córdoba, Universidad, Inst. ${ }^{\circ}$ de Historia de Andalucía, 1977.

20 Porro Herrera, M. a José: «Prensa cordobesa del siglo XX: una aproximación», en Boletín de la Real Academia de Ciencias, Bellas Letras y Nobles Artes de Córdoba, Julio-Diciembre, 1994; LXV, n. ${ }^{\circ}$ 127; pp. 397-414

21 Esteve Botey, Francisco: Historia del grabado. Barcelona / Buenos Aires, Labor, 1935, p. 13.

22 Ainaud, Juan: «Grabado y encuadernación», en Ars Hispaniae: Historia Universal del Arte Hispánico. T. XVIII, Madrid, 1958.

23 Ceán Bermúdez, Juan Agustín: Diccionario Histórico de los más ilustres proresores de las Bellas Artes en España. Madrid, Reales Academias de Bellas Artes de San Fernando y de la Historia, 1965 (ed. facsímil), T. II, p. 133, y Viñaza: Adiciones al Diccionario Histórico de los más ilustres profesores de las Bellas Artes en España, de D. Juan Agustín Ceán Bermúdez. Madrid, 1894, T. II.

24 Gállego, Antonio: Historia del grabado en España. Madrid, Cátedra, 1979; p. 343. 
25 «En cuanto a los numerosos libros sin fecha y sin nombre de impresor, sólo la experiencia nos ha enseñado a fecharlos: el frontispicio presenta, a veces, alguna xilografía o un motivo tipográfico, que difiere según los siglos. De la misma manera, los caracteres tipográficos, la impresión, los sistemas de ordenación y paginación del texto, los adornos, las mayúsculas, las letras de pie de página permiten, no habiendo ninguna fecha, decir si el texto es del siglo XVIII". Geneviève Bollème: "Literatura popular y comercio ambulante del libro en el siglo XVIII", en Libros, editores y público en la Europa Moderna. Ed. Armando Petrucci. Valencia, Edicions Alfons el Magnànim, 1990; pp. 207-246.

26 Cfr. "Lectura y Contrarreforma», por Dominique Julia y «Lecturas y lectores 'populares' desde el Renacimiento hasta la época clásica", por Roger Chartier, en Historia de la lectura en el mundo occidental, Dir. Guglielmo Cavallo y Roger Chartier. Madrid, Taurus, 1998; pp. 367-412 y 413-434.

27 Iglesias Tais, Manuel y Antonio Flores: Catálogo de incunables e impresos del XVI de la Biblioteca Pública de Córdoba. Córdoba, Consejería de Cultura. Junta de Andalucía, 1986.

28 «Siendo el convento de San Pablo cuartel de uno de los cuerpos que se levantaron y llamaron "francos" vulgarmente "peseteros" [...] vieron cerrada la pieza de la biblioteca $y$, sin duda creyendo encontrar algo de valor que robar [...] lograron penetrar en ella y principiaron a sacar libros y a venderlos en las tiendas y boticas, o por lo que les daban. Cuando yo tuve noticia de esto y di cuenta a la comisión, era ya tarde, y cuando se puso en cobro habían extraido ya gran número de libros, entre los cuales había algunos muy curiosos y de valor, que yo, aunque sólo había visto la biblioteca muy por cima, eché de menos desde luego. De aquí resultó quedar muchas obras incompletas». Luis M. ${ }^{a}$ Ramírez de las Casas-Deza: Memorias, p. 91.

29 Porro Herrera, M. a José: «La Biblioteca Pública Provincial de Córdoba. II. Procedencia de algunos volúmenes que integran su fondo bibliográfico antiguo", en Axerquía. Revista de Estudios Cordobeses, n. ${ }^{\circ}$ 8, septiembre, 1983; pp. 9-42.

30 Flores Muñoz, Antonio: «La Biblioteca Pública Provincial de Córdoba: fondos Bibliográficos», en Universiíario, año I, n. ${ }^{\circ}$, pp. 10-11 y «La biblioteca del antiguo convento de PP. Capuchinos de la ciudad de Córdoba (1633-1835)", en Estudios Franciscanos, 96, 1995; pp. 389-424.

31 Weruaga Prieto, Antonio: Libros y lectores en Salamanca. Del Barroco a la Ilustación: 1650-1725. Salamanca, Junta de Castilla y León, 1993; p. 47.

32 Cfr Art. Cit. p. 387.

33 «Dio esta elibro lalibreria de este Convento al M. ${ }^{\circ}$ fr. Antonio de Mata, con condiciones de poderlo llebar asu zelda, si en algunas ocasiones los necesitase, i visto lo restituya aella", Antonio Bravo Allegacion en favor de la Jurisdiscion de los Prelados de las Religiones.

34 Cfr. Art. cit. p. 417.

35 Wittmann, Reinhard: «¿Hubo una revolución en la lectura a finales del siglo XVIII?", en Historia de la lectura en el mundo occidental, Dir. Guglielmo Cavallo y Roger Chartier. Madrid, Taurus, 1998; pp. 435-472.

36 En Alemania como en Francia «la nobleza rural no llega a adquirir libros hasta concluido el siglo [...] El número de nobles de la corte, y sobre todo los del campo, que reunieron valiosas colecciones en calidad de bibliófilos, era muy reducido. No desempeñaron un papel relevante en esta "revolución" de la lectura" (opus cit. p. 449). Y si esto sucedía en el resto de Europa ¿Qué decir de la nobleza rural cordobesa? 
$3794 \%$ en 1800 ; $90 \%$ en 1840 para una población entre 11 y 14 millones de habitantes, siendo para la población femenina en 1860 , el 85 '9\% sobre el 75 '5\% que es la media nacional. Cfr. Rosa M. ${ }^{a}$ Capel: El trabajo y la educación de la mujer en España (1900-1930). Madrid, M. ${ }^{\circ}$ de Cultura, 1982, p. 325. Cfr. también Luzuriaga: El analfabetismo en España. Madrid, 1926.

38 Aguilar Piñal, Francisco: Romancero popular del siglo XVIII. Madrid, C.S.I.C., Cuadernos Bibliográficos, n. ${ }^{\circ}$ 27, 1972; p. XIII.

39 Aguilar Piñal, Francisco Opus cit. p. XIV.

40 Porro Herrera, M. ${ }^{\circ}$ José: “Doña Catalina Manzano, ejemplo de transgresión lectora constante y soterrada", en Glosa Anuario del Departamento de Filología Española y sus didácticas. n. ${ }^{\circ}$ 2, 1991; pp. 243-253.

41 Porro Herrera, M. ${ }^{a}$ José: Art. cit.

42 Lyons, Martyn: "Los nuevos lectores del siglo XIX", en Historia de la lectura el mundo occidental, Dir. Guglielmo Cavallo y Roger Chartier. Madrid, Taurus, 1998; pp. 473-517.

43 Martínez Martín, Jesús: Lectura y lectores en el Madrid del siglo XIX. Madrid, C.S.I.C. 1991; p. 81.

44 Díaz del MORAL, Juan: Historia de las agitaciones campesinas andaluzas. Madrid, Alianza Universidad, 1984, $4^{a}$ ed. p 188.

45 FLores Muñoz, Antonio: Art. cit., en Universitario. 